\title{
A randomized, controlled trial of high dose, inhaled budesonide versus oral prednisone in patients discharged from the emergency department following an acute asthma exacerbation
}

\begin{abstract}
J Mark FitzGerald MD FRCPC ${ }^{1}$, David Shragge MD FRCPC ${ }^{5}$, Jennifer Haddon MSc ${ }^{6}$, Barbara Jennings $\mathrm{PhD}^{6}$, Joanna Lee M Math ${ }^{6}$, Tony Bai MD FRCPC ${ }^{3}$, Peter Pare MD FRCPC ${ }^{3}$, David Kassen MD FRCPC ${ }^{4}$, Anton Grunfeld MD FRCPC ${ }^{2}$ ${ }^{1}$ The Respiratory Division and ${ }^{2}$ Department of Emergency Medicine, Vancouver General Hospital, Vancouver, British Columbia, and the University of British Columbia, ancouver, British Columbia; ${ }^{3}$ The Respiratory Division and ${ }^{4}$ the Emergency Department, St Paul's Hospital, Vancouver, British Columbia and The University of British Columbia; and ${ }^{5}$ Misericordia Hospital, University of Alberta, Edmonton, Alberta; and ${ }^{6}$ the Medical Department, Astra Pharma Inc, Toronto, Ontario
\end{abstract}

JM FitzGerald, D Shragge, J Haddon, et al. A randomized, controlled trial of high dose, inhaled budesonide versus oral prednisone in patients discharged from the emergency department following an acute asthma exacerbation. Can Respir J 2000;7(1):61-67.

OBJECTIVE: Prednisone (PRED) is recommended at discharge to reduce the relapse rate following emergency treatment for an asthmatic attack. However, PRED has systemic side effects. Inhaled anti-inflammatory medications, such as budesonide (BUD), are well tolerated. This study was designed to compare the effectiveness of PRED and BUD on relapse rate.

DESIGN: A prospective, randomized, double-blind, double dummy, parallel group design.
SETTING: Tertiary referral emergency departments.

POPULATION STUDIED: One hundred and eighty-five patients with acute asthma who received standard treatment with bronchodilators and systemic glucocorticosteroids in the emergency department, had a forced expiration volume in $1 \mathrm{~s}\left(\mathrm{FEV}_{1}\right)$ greater than $50 \%$ predicted and who were deemed well enough to be discharged from the emergency department. INTERVENTION: Patients were randomized to receive either BUD Turbuhaler $600 \mu \mathrm{g}$ qid or PRED $40 \mathrm{mg}$ in the morning for seven to 10 days. At discharge and final visit, symptoms, medication use, $\mathrm{FEV}_{1}$, peak expiratory flow (PEF) and quality of life (QoL) were assessed. Relapse rate to the emergency department during the follow-up was determined by a yes and/or no questionnaire.

continued on next page

Correspondence and reprints: Dr J Mark FitzGerald, Respiratory Clinic, Vancouver Hospital and Health Sciences Centre, 2775 Heather Street, Vancouver, British Columbia V5Z 1J5. Telephone 604-875-4122, fax 604-875-4695, e-mail markf@interchange.ubc.ca 
MAIN RESULTS: The PRED ( $\mathrm{n}=85)$ and BUD $(\mathrm{n}=90)$ treatment groups were comparable at baseline (emergency department discharge) for age (mean \pm SD; 27.6 \pm 8.5 years and $29.2 \pm 8.7$ years) and prebronchodilator $\mathrm{FEV}_{1}(1.77 \pm 0.79 \mathrm{~L}$ and $1.75 \pm 0.78 \mathrm{~L}$ ), respectively. BUD was at least as effective as PRED in preventing a relapse to the hospital; relapse rate was $10(11.8 \%)$ during PRED treatment and nine $(10.0 \%)$ for BUD treatment (95\% CI PRED-BUD, $-7.5 \%$ to $11.0 \%$ ). Improvements in $\mathrm{FEV}_{1}$, asthma symptoms, PEF and $\mathrm{QoL}$ were not significantly different between treatments.

CONCLUSIONS: In patients whose acute asthma has been stabilized in the emergency department, high dose BUD may be an alternate to PRED as a follow-up treatment.

Key Words: Acute asthma; Budesonide; Emergency department; Inhaled glucocorticosteroids; Turbuhaler

Essai randomisé contrôlé sur le budésonide par inhalation à forte dose versus prednisone orale chez des patients ayant reçu leur congé des urgences après une crise d'asthme aiguë

OBJECTIF : La prednisone est recommandée au moment du congé pour réduire le taux de rechute après le traitement d'une crise d'asthme aux urgences. Par contre, elle exerce des effets secondaires systémiques. Les médicaments anti-inflammatoires par inhalation comme le budésonide sont bien tolérés. Cette étude a été mise sur pied pour com- parer l'efficacité de la prednisone et du budésonide à faire diminuer le taux de rechute.

MODÈLE : Modèle prospectif randomisé, à double insu, avec double placebo et groupe parallèle.

CONTEXTE : Service des urgences d'hôpitaux de soins tertiaires.

POPULATION ÉTUDIÉE : Cent quatre-vingt-cinq patients présentant une crise d'asthme et ayant été traités au moyen de thérapeutiques habituelles par bronchodilatateurs et glucocorticostéroïdes systémiques dans un service d'urgence; ils présentaient un VEMS supérieur à $50 \%$ par rapport aux valeurs prévues et avaient été jugés suffisamment bien pour recevoir leur congé.

INTERVENTION : Les patients ont été assignés aléatoirement au budésonide par Turbuhaler $600 \mu \mathrm{g}$ q.i.d. ou à la prednisone $40 \mathrm{mg}$ le matin pendant sept à dix jours. Au moment du congé et de la visite finale, les symptômes, l'emploi des médicaments, le VEMS, le débit expiratoire de pointe et la qualité de vie ont été mesurés. Le taux de rechute (retour aux urgences) durant la période de suivi a été déterminé au moyen d'une formule composée de questions fermées.

PRINCIPAUX RÉSULTATS : Les groupes traités à la prednisone (n $=85)$ et au budésonide $(\mathrm{n}=90)$ étaient comparables au début (au moment du congé) pour ce qui est de l'âge (moyenne \pm É.-T.; 27,6 $\pm 8,5$ ans et $29,2 \pm 8,7$ ans) et du VEMS avant la bronchodilatation $(1,77 \pm 0,79 \mathrm{~L}$ et $1,75 \pm 0,78 \mathrm{~L}$ ) respectivement. Le budésonide s'est révélé au moins aussi efficace que la prednisone à prévenir la rechute. Le taux de rechute a été de $10(11,8 \%)$ lors du traitement à la prednisone et de $9(10,0 \%)$ durant le traitement au budésonide (I.C. 95 \%; PRED-BUD, - 7,5\% à $11,0 \%$ ). Les améliorations du VEMS et des symptômes de l'asthme, du débit respiratoire de pointe et de la qualité de vie n'ont pas été significativement différentes entre les deux groupes.

CONCLUSIONS : Chez les patients dont la crise d'asthme aiguë a été stabilisée au service des urgences, du budésonide à forte dose peut servir de solution de rechange à la prednisone en traitement de suivi.
$\mathrm{T}$ he management of acute asthma in the emergency department involves the use of bronchodilator therapy primarily with inhaled beta2-agonists (1) and, less often, ipratropium bromide (2), oxygen (1) and systemic glucocorticosteroids (GCSs) (3). Historically, steroids were given intravenously (4), but more recently, the use of oral GCSs has been recommended $(5,6)$. Despite these recommendations, the management of acute asthma has been documented as suboptimal in the past (7), and, although improvements were noted in a recent survey (8), management still did not match published guidelines (9). The reasons for suboptimal management of acute asthma are unclear because it has been shown that prednisone (PRED) given at the time of discharge reduces significantly the relapse rate to the emergency department (10). In the past, a 10 to 14 day course of PRED was usually followed by a tapering dose of PRED. More recently, with inhaled GCSs, it was found that no tapering was required (11).

The impact of multiple short courses of oral PRED is unknown, and some patients have documented significant psychological reactions to systemic steroids, which makes them reluctant to take PRED. Inhaled GCSs have been shown to have fewer systemic effects (12). Asthma management might be improved if equivalence between PRED and budesonide Turbuhaler (Astra Pharma Inc, Mississauga) (BUD) could be demonstrated for follow-up of an acute exacerbation. The primary objective of this study was to compare the incidence of asthma relapse during one week of treatment with a high dose of PRED or inhaled BUD in patients who were deemed well enough to be discharged from the emergency department following a severe acute asthma attack. The second objectives of this study were to compare the effects of BUD and PRED on forced expiration volume in $1 \mathrm{~s}\left(\mathrm{FEV}_{1}\right)$, peak expiratory flow (PEF), asthma symptoms and quality of life (QoL) results (13).

\section{PATIENTS AND METHODS}

Patient characteristics: Patients 15 to 70 years of age were recruited in the emergency department after having an acute asthma exacerbation (a progressive increase in dyspnea and a history of asthma as defined by the American Thoracic Society criteria) (14). Patients had to be well enough to be discharged (postbronchodilator FEV1 greater than 50\% of predicted normal) (9). Postbronchodilator reversibility of greater than $15 \%$ was documented for FEV1 or greater than $20 \%$ for PEF compared with baseline, to establish the diagnosis of asthma and exclude patients who had chronic obstructive lung disease. Patients with chronic obstructive lung disease would not have reversible air flow obstruction and by showing reversible air flow obstruction, we confirm the diagnosis of asthma. All patients had to be able to use Turbuhaler correctly.

Exclusion criteria were as follows: intolerance to oral GCSs or inhaled GCSs; peptic ulcer disease; active tuberculosis; fungal infection; or insulin-dependent diabetes. Patients who had moderate to severe hypertension (diastolic blood pressure greater than $105 \mathrm{mmHg}$ ) and patients who were pregnant, lactating or of childbearing age and not using effective means of contraception, were excluded. Patients were also excluded if they had received a course of oral 
GCSs in the four weeks before visit 1 or if they required more than $1600 \mu \mathrm{g} /$ day of inhaled GCS as maintenance therapy. Additionally, patients who had major comorbid illnesses that might interfere with the study outcomes were excluded.

One hundred and eighty-five patients who had acute asthma presented to the three university-affiliated, urban emergency departments. These patients fulfilled the inclusion and none of the exclusion criteria and were placed randomly in the study (175 patients were eligible for the intent-to-treat group).

Study design: The randomized, controlled trial was a double- blind, double dummy, parallel group design. Patients were treated with bronchodilators and supplemental oxygen at the discretion of the emergency department staff. All patients were required to receive one dose of systemic GCSs, either methylprednisolone $125 \mathrm{mg}$ intravenously or oral PRED 40 to $60 \mathrm{mg}$ before randomization. Eligible patients were then randomly placed in groups for treatment with inhaled BUD $2400 \mu \mathrm{g} / \mathrm{day}$ (the approved maximum dose in Canada) given in divided doses qid or PRED $40 \mathrm{mg}$ once daily in the morning. Patients were also stratified into two groups based on their regular inhaled GCS requirement during the month before presentation to the emergency department (less than or equal to $400 \mu \mathrm{g}$ for stratum one and greater than $400 \mu \mathrm{g}$ for stratum two).

Treatment continued for seven to 10 days after emergency department discharge. After four days, telephone contact to assess asthma control was attempted for each patient. All patients were scheduled for a return visit seven to 10 days after emergency department discharge. In the event of a deterioration in lung function, the patient was asked to return to the emergency department earlier. Patients who failed to return for the final visit were contacted by telephone, and encouraged to come in for a visit and return the study medication. If the patient could not return for a visit, the study staff attempted to obtain, over the telephone, current peak flow measurements, symptom scores and information about any possible asthma relapses. Patients were also given instructions on how to taper their study medications.

Study drugs: BUD Turbuhaler and its placebo were manufactured by Astra Pharmaceutical Production AB (Sodertalje, Sweden). PRED and its placebo were supplied by the Pharmacia Upjohn Company (Toronto). The active and placebo treatments (Turbuhaler devices and PRED tablets) were identical in appearance. As a measure of compliance, the remaining doses in each Turbuhaler were counted and an estimate of the number of doses taken was calculated. The number of pills returned was used in calculation of compliance.

Treatment plan: Patients fulfilling the inclusion and with none of the exclusion criteria, were discharged with BUD $2400 \mu \mathrm{g} /$ day (three inhalations of $200 \mu \mathrm{g}$, qid) or placebo with a suggested schedule and PRED or placebo $40 \mathrm{mg} /$ day. Following discharge from the emergency department, patients were requested to continue on prestudy doses of theophylline and ipratropium, but not to take their prestudy inhaled GCSs. Patients were also instructed to use only their short-acting beta2-agonist for symptomatic relief. The study drug was continued for at least seven to 10 days depending on the day patients returned.

Ethical conduct and review: Hospital and University approval for this study was received from the centres' Ethics Review Boards before the study started. Patients gave their informed consent before enrolment in the study. The study was performed in accordance with the principles stated in the 'Guidelines on Research Involving Human Subjects' issued by the Medical Research Council of Canada, which encompasses the Declaration of Helsinki.

Clinical assessments: Demographic data, concomitant medications and disease, and medical history were documented at baseline after treatment in the ED. At baseline and at visit 2, before and 30 mins after, postbronchodilator spirometry was performed. The highest of three measurements for $\mathrm{FEV}_{1}, \mathrm{PEF}$ and when possible, for forced vital capacity was documented to assess lung function.

When the patient was at home, asthma severity was selfassessed each evening for the previous $24 \mathrm{~h}$ as follows: 0 equals no symptoms; 1 equals mild symptoms present but not troublesome; 2 equals moderate symptoms present but not sufficient to interfere with daily activities; or 3 equals severe symptoms sufficiently troublesome to interfere with normal activity. PEF was also measured and recorded at home in the morning and evening using a mini-Wright (Clement Clark International Ltd, Essex, United Kingdom) peak flow meter before patients took their study medications. Study drugs and other medications were recorded in the diary card and on the case report form. In the event of a sore throat or thrush, swabs for candida were completed when deemed necessary by the physician, but there were no reports of candida during this study. The self administered Asthma Quality of Life Questionnaire (AQLQ) (13) was completed by the patient at baseline and at visit 2 . During the study period, adverse events were documented by spontaneous reporting of symptoms and after visit 2 by asking if any health problems had been experienced since the last emergency department visit.

Statistical determination of sample size: The main objective of this study was to determine if the two treatments were clinically equivalent. A difference in relapse rate of greater than $10 \%$ was considered a priori to be clinically significant (15). If both treatments had a relapse rate of $5 \%, 75$ evaluable patients were required in each group (150 in total). This calculation was based on a two-sided $\chi^{2}$ test without continuity correction at alpha $=0.05$ with power $(1-B)=80 \%$. The null hypothesis stated that the absolute treatment difference was greater than or equal to $10 \%$, while the alternate hypothesis assumed that the absolute treatment difference was less than $10 \%$. In relation to conventional hypothesis testing, the meaning of alpha and beta is reversed (ie, alpha is the risk of falsely rejecting the hypothesis of nonequivalence and $[1-B]$ was the probability of accepting the hypothesis of equivalence, when it was true).

Statistical methods and analysis plans: The principal outcome measure was the relapse rate, defined as a return to the ED. Secondary efficacy variables were measurements of $\mathrm{FEV}_{1}$ (in the daily diary and in the clinic) during the study 
TABLE 1

Patient demographics, forced expiration volume in $1 \mathrm{~s}\left(\mathrm{FEV}_{\mathbf{1}}\right)$, respiratory medication at baseline and compliance with study drugs in a randomized, controlled trial of high dose, inhaled budesonide versus oral prednisone in patients discharged from the emergency department following an acute asthma exacerbation

\begin{tabular}{|c|c|c|c|}
\hline Characteristics & $\begin{array}{l}\text { Prednisone } \\
\text { group }\end{array}$ & $\begin{array}{l}\text { Budesonide } \\
\text { group }\end{array}$ & Total \\
\hline Number of patients & 85 & 90 & 175 \\
\hline Weight $(\mathrm{kg})^{*}$ & $69.3 \pm 15.1$ & $69.1 \pm 14.6$ & $69.2 \pm 14.8$ \\
\hline Height $(\mathrm{cm})^{\star}$ & $168.3 \pm 8.0$ & $169.4 \pm 10.3$ & $168.9 \pm 9.2$ \\
\hline Number male (number female) & $37(48)$ & $38(52)$ & 75 (100) \\
\hline Postbronchodilator* & $75.7 \pm 16.6$ & $74.0 \pm 16.5$ & $74.8 \pm 16.5$ \\
\hline Number of patients & 74 & 78 & 152 \\
\hline Compliance* $^{*}$ & $99.3 \pm 5.5$ & $96.8 \pm 26.0$ & $98.0 \pm 19.0$ \\
\hline Other & $21(42 \%)$ & 29 (58\%) & 50 \\
\hline
\end{tabular}

*Mean( $\pm S D)$. Intent-to-treat population

TABLE 2

Reasons for discontinuing the study of a randomized, controlled trial of high dose, inhaled budesonide versus oral prednisone in patients discharged from the emergency department following an acute asthma exacerbation

\begin{tabular}{lccc}
\hline Reason & $\begin{array}{c}\text { Prednisone } \\
\text { group (n) }\end{array}$ & $\begin{array}{c}\text { Budesonide } \\
\text { group (n) }\end{array}$ & Total (n) \\
\hline Adverse event & 5 & 7 & 12 \\
Lost to follow-up & 10 & 4 & 14 \\
$\begin{array}{l}\text { Patient wanted to } \\
\text { stop study }\end{array}$ & 3 & 3 & 6 \\
$\begin{array}{l}\text { Family doctor } \\
\quad \begin{array}{l}\text { wanted patient to } \\
\text { stop study }\end{array}\end{array}$ & 0 & 1 & 1 \\
Relapse & 1 & 0 & 1 \\
\hline
\end{tabular}

$n$ Number of patients

period. The changes from baseline to the end of treatment for $\mathrm{FEV}_{1}$ (before and after bronchodilator) and PEF were compared between the two treatment groups. Secondary variables were the changes in symptom scores and AQLQ. Parametric and nonparametric tests were used for the comparisons where applicable. Two-tailed tests of significance were used. $\mathrm{P}<0.05$ was considered statistically significant.

Analysis was performed using a modification of the intent-to-treat approach that is termed all patients treated. In this approach, all patients who have been randomized to treatment and who received at least one dose of study drug were considered for inclusion in the analysis except for patients who discontinued treatment an early stage because of baseline characteristics, or who had no measurements of effi- cacy made during the treatment period. In addition, patients with only visit 1 and no diary card data were excluded from the analysis. These criteria were decided a priori and included in the initial study protocol. All decisions regarding the statistical analysis were made before breaking the study code, and all results were expressed with a $95 \%$ CI of treatment difference.

Logistical regression was used to test for a centre effect and the significance of $\mathrm{FEV}_{1}$ at baseline for the primary variable (relapse rate). The results of the regression showed no significant effect for either of these variables, so they were excluded from subsequent analysis. Analysis of covariance (ANCOVA) with the three factors (ie, treatment, centre and treatment-by-centre interaction) was used for $\mathrm{FEV}_{1}, \mathrm{PEF}$, symptoms scores and AQLQ scores. As well, the baseline value was incorporated in the model as a covariate for postbronchodilator $\mathrm{FEV}_{1}$ as a percentage of predicted normal, PEF, symptom scores and AQLQ results, respectively.

The changes in $\mathrm{FEV}_{1}$ from baseline to visit 2 were analyzed by ANCOVA. The area under the curve was calculated per patient from day 1 to day 10 for diary variables (PEF in the morning, PEF in the evening and symptom scores). Data analysis was performed using SAS version V6.08 under VMS IVAX V6.1 (SAS Institute, Cary, North Carolina).

\section{RESULTS}

One hundred and eighty-five patients were enrolled and placed randomly into the study groups. Eight patients (five PRED and three BUD) were soon lost to follow-up. Two further patients were excluded, both from the PRED group; one patient did not have asthma and the second received both active treatments. Thus, 10 patients were excluded from the analysis. The two treatment groups were comparable at base- 
TABLE 3

Mean forced expiration volume in $1 \mathrm{~s}\left(\mathrm{FEV}_{1}\right)(\mathrm{L})$ and peak expiratory flow (L/min) before and after bronchodilator use in a randomized, controlled trial of high dose, inhaled budesonide versus oral prednisone in patients discharged from the emergency department following an acute asthma exacerbation

\begin{tabular}{lcc}
\hline Characteristic & $\begin{array}{c}\text { Prednisone } \\
\text { group }\end{array}$ & $\begin{array}{c}\text { Budesonide } \\
\text { group }\end{array}$ \\
\hline Pre-FEV $_{1}(\mathrm{~L})$ & & \\
Visit 1 & $1.77 \pm 0.79$ & $1.75 \pm 0.78$ \\
Visit 2 & $3.00 \pm 0.85^{\star}$ & $3.06 \pm 0.85^{\star}$ \\
Post-FEV 1 (L) & & \\
Visit 1 & $2.74 \pm 0.67$ & $2.71 \pm 0.80$ \\
Visit 2 & $3.29 \pm 0.85^{\star}$ & $3.34 \pm 0.91^{\star}$ \\
& & \\
Pre-PEF (L/min) & & \\
Visit 1 & $238.6 \pm 89.7$ & $249.7 \pm 117.2$ \\
Visit 2 & $457.2 \pm 94.6^{*}$ & $453.0 \pm 112.8^{\star}$ \\
Post-PEF (L/min) & & \\
Visit 1 & $410.3 \pm 85.8$ & $403.0 \pm 116.1$ \\
Visit 2 & $487.1 \pm 100.2^{*}$ & $485.7 \pm 115.4^{*}$ \\
\hline
\end{tabular}

Mean $( \pm S D)$. No significant differences between treatments. ${ }^{*} P<0.05$ improvement from baseline

line (Table 1) in terms of age, weight, height and sex. The estimation of compliance with study medications was high and comparable between the treatment groups (99.3\% PRED and 96.8\% BUD).

Thirty-four patients withdrew from the study for various reasons. Table 2 summarizes the main reasons for withdrawal, which were adverse events and patients lost to follow-up (ie, the patient was unreachable after discharge so no relapse information could be obtained). The most common adverse events were dyspepsia ( $n=2$ PRED, $n=7$ BUD), nausea ( $n=4$ PRED, $n=6$ BUD) and headache ( $n=6$ PRED, $n=4$ BUD), and were only of mild and moderate intensity. Twelve patients withdrew from the study because of an adverse event; six patients who received at least one dose of BUD withdrew because of an asthma exacerbation. Of the five patients who received PRED, one withdrew because of a 'funny-taste in their mouth, increased appetite, nausea and shakiness' and four withdrew because of an asthma exacerbation (these relapses were included in the total count with the patients who relapsed but did not discontinue from the study).

The relapse rate was comparable between the PRED and BUD treatment groups (10 relapses and nine relapses, respectively). The $95 \% \mathrm{CI}$ of treatment difference (ie, $-7.5 \%$ to $11 \%$ ) showed that BUD was at least as effective as PRED. The improvements with treatment for both $\mathrm{FEV}_{1}$ and PEF (Table 3) were not significantly different between BUD and PRED treatment groups. As expected, there was a significant improvement over time for both groups for prebronchodilator $\mathrm{FEV}_{1}(49 \%$ to $82 \%$ PRED and $47 \%$ to $83 \%$ BUD) and for PEF.

Asthma symptoms and AQLQ results (Table 4) showed a similar pattern with comparable improvements for the BUD and PRED treatment groups and the expected significant improvement over time with both treatments.
TABLE 4

Descriptive statistics of the mean total score for Asthma Quality of Life Questionnaire (AQLQ) in a randomized, controlled trial of high dose, inhaled budesonide versus oral prednisone in patients discharged from the emergency department following an acute asthma exacerbation

\begin{tabular}{lcc}
\hline Total-AQLQ & $\begin{array}{c}\text { Prednisone } \\
\text { group }\end{array}$ & $\begin{array}{c}\text { Budesonide } \\
\text { group }\end{array}$ \\
\hline Baseline & 85 & 90 \\
Number & $3.65(0.94)$ & $3.99(0.94)$ \\
Mean $( \pm \mathrm{SD})$ & 1.8 & 1.6 \\
Minimum & 6.0 & 6.2 \\
Maximum & & \\
Visit 2 & 73 & 79 \\
Number & $5.11(1.00)$ & $5.15(1.19)$ \\
Mean $( \pm \mathrm{SD})$ & 1.5 & 1.9 \\
Minimum & 6.6 & 7.0 \\
Maximum & & \\
Change from baseline to visit 2 & 73 & 79 \\
Number & $1.42(1.07)^{\star}$ & $1.16(1.23)$ \\
Mean $( \pm$ SD) & -0.7 & -2.9 \\
Minimum & 3.8 & 3.7 \\
Maximum & & \\
\hline
\end{tabular}

No significant differences between treatments. ${ }^{\star} P<0.05$ improvement from baseline

\section{DISCUSSION}

This study has shown that patients can be discharged safely from the emergency department on high dose inhaled BUD instead of oral PRED. The two treatments were shown to be equivalent. There were no significant differences in the side effects profile between the groups. The doses of oral GCSs and inhaled GCSs in this study were chosen based on the findings of Toogood et al (12) who showed that $2000 \mu \mathrm{g}$ of BUD, by inhalation, resulted in an equivalent antiinflammatory effect as $40 \mathrm{mg}$ of oral PRED. Because there was approval for $2400 \mu \mathrm{g}$ BUD in Canada, we chose to use this higher dose. We also used a four-times daily regimen because an earlier study by Malo et al (16) demonstrated that a qid dosing schedule in ambulatory people with asthma gave better control than a twice-daily regimen. However, it appears that a lower dose of BUD is just as effective (17). A study performed in Thailand (17) showed similar results to ours for spirometry. In that study, 81 patients were randomly selected to receive $1600 \mu \mathrm{g}$ of BUD or $40 \mathrm{mg}$ of PRED tapered daily over seven days. Despite the early PRED taper, there were no differences for $\mathrm{FEV}_{1}$, PEF or rescue medication use between the groups. It could be argued that the comparison made in this study (17) was not representative of current practice in which is PRED is given for seven to 14 days before tapering begins (9). Thus, patients in the PRED arm were undertreated.

To the authors' knowledge, this is the first North American study to address the issue of substitution of oral GCSs with high dose inhaled GCSs for the follow-up treatment of patients with asthma severe enough to require management of an acute exacerbation in the emergency department. A larger, family physician, office-based study in the United 
Kingdom compared high dose fluticasone propionate $(n=206)$ with oral prednisolone $(n=207)$ in patients who had less severe airflow obstruction (18). Patients were randomized to receive either $2000 \mu \mathrm{g} /$ day of fluticasone propionate or a tapering dose of prednisolone $40 \mathrm{mg}$. The setting for the study ensured that the patients were less sick (ie, PEF of $75.1 \%$ of predicted normal) than the patients in the current study, who presented with a prebronchodilator $\mathrm{FEV}_{1}$ of $45 \%$ of predicted normal. In an accompanying editorial, Griffiths (19), although welcoming the British study, indicated the need for sicker patients to be studied. We have achieved this objective in the current study. In addition, there have been a number of smaller studies published that have addressed the issue of adjunct inhaled corticosteroid in acute asthma (2022).

It has been suggested that QoL is an important outcome and should be assessed in clinical trials of asthma interventions (13). The AQLQ has been shown to be a reliable, valid and responsive instrument for use in the follow-up of patients discharged after an acute asthma exacerbation (20). In our study, QoL provided important feedback about the patients' health, as shown by the improvement in well being. Clinical improvement by objective measures occurred in parallel to that for QoL. This is in agreement with a preliminary study in which we showed a clear difference in asthma QoL between patients hospitalized for acute asthma compared with community controls (21).

There were no major differences in the adverse event profiles in the treatment groups. Despite this, there have been reports of idiosyncratic reactions to short courses of oral GCSs (22), especially in sicker patients when combined with neuromuscular relaxing agents and when the corticosteroids were given intravenously (23), myopathy has been reported. A potential argument against using high dose inhaled GCSs compared with oral PRED is cost. Based on current recommendations, most asthma patients who are likely to have an exacerbation should already be taking inhaled GCSs because its use has been shown to reduce their risk of death (24). A logical extension of our study would be confirmation that an increase in inhaled GCSs in the early stages of an exacerbation would prevent the exacerbation from progressing to the extent that a visit to the emergency department is required. Given the documented high costs of asthma care delivered by emergency departments and hospitalizations $(25,26)$, the use of high dose inhaled GCSs in the manner described in this study at an earlier stage may be more cost effective in the long term. Such a result will only be achieved if asthma patients are educated to manage their disease proactively (to be able to change therapy, ie, increase anti-inflammatory therapy early in an asthma exacerbation) (27) and to use their predetermined action plan early (28).

Recently, a study has been published that extends our results; Rowe and colleagues (29) randomized patients to oral PRED versus PRED and $1600 \mu \mathrm{g}$ of BUD after discharge from the emergency department. In the combination arm of the study, the relapse rate was $12.8 \%$ compared with $24.5 \%$ in the placebo (PRED alone) arm of the study. These intrigu- ing results need to be treated cautiously because the rate of relapse in the PRED alone group is close to that of placebo groups in previously published studies. The longer and more comprehensive follow-up in the recent study may account for these differences. These new data, as well as the recent study by Rodrigo and Rodrigo (30), suggest that inhaled GCSs may have an important complimentary role to systemic PRED in the management of acute asthma. The Uruguay study (30) showed that the addition of flunisolide $1 \mathrm{mg}$ every 10 mins in the first $3 \mathrm{~h}$ of an acute asthma attack, along with inhaled salbutamol, gave a significantly better bronchodilator response $(\mathrm{P}=0.041)$ than salbutamol alone.

Our study has a number of limitations, most notably, a relatively high loss to follow-up and small sample size. In terms of loss to follow-up, seven of the 10 patients with no follow-up were in the PRED group, thus, if anything, their inclusion would be likely to skew the results in favour of PRED. In addition, in showing equivalence of relapse rate, the CI crossed $10 \%$, which was the a priori level set as significant. However, the 95\% CI was calculated based on PRED minus BUD. Thus, the upper limit of the CI actually exceeded the a priori clinically relevant relapse rate of $10 \%$. We therefore feel justified in saying that we have shown at least equivalence. Despite these limitations, we feel our results in conjunction with other, more recent smaller studies $(31,32$,$) suggest that high dose inhaled corticosteroids have a$ role to play in acute asthma. Further studies need to address the optimal dose and duration of inhaled therapy as well as the benefits of combination therapy. The cost effectiveness of such regimens also need to be determined.

ACKNOWLEDGEMENT: Supported by a grant from Astra Pharma Inc

\section{REFERENCES}

1. FitzGerald JM, Grunfeld A. Status asthmaticus. In: Lichetenstein LM, Fauci AS, eds. Current Therapy in Allergy, Immunology and Rheumatology. St Louis: Mosby, 1996:63-7.

2. FitzGerald JM, Grunfeld A, Pare PD, et al. The clinical efficacy of combination nebulized anticholinergic and adrenergic bronchodilators vs nebulized adrenergic bronchodilator alone in acute asthma. Canadian Combivent Study Group. Chest 1997;111:311-5.

3. Engel T, Heinig JH. Glucocorticosteroid therapy in acute severe asthma - a critical review. Eur Respir J 1991;4:881-9.

4. McFadden ER Jr. Dosages of corticosteroids in asthma. Am J Respir Dis 1993;147:1306-10.

5. Rowe BH, Keller JL, Oxman AD. Effectiveness of steroid therapy in acute exacerbations of asthma: a meta-analysis. Am J Emerg Med 1992;10:301-10.

6. FitzGerald JM, Kearon MC. Corticosteroids in acute asthma; results of a meta-analysis. Am Rev Respir Dis 1991;143(Pt 2):624. (Abst)

7. FitzGerald JM, Hargreave FE. Emergency department management of acute asthma and prospective evaluation of outcome. CMAJ 1990;142:591-5.

8. Grunfeld A, Beveridge RC, Bekowitz J, FitzGerald JM. Management of acute asthma in Canada: an assessment of physician behaviour. J Emer Med 1997;5:547-56.

9. Beveridge RC, Grunfeld AF, Hodder RV, Verbeek PR. Guidelines for the emergency management of asthma in adults. CAEP/CTS Asthma Advisory Committee. Canadian Association of Emergency Physicians and the Canadian Thoracic Society. CMAJ 1996;155:25-37.

10. Chapman KR, Verbeek PR, White JG, Rebuck AS. Effect of a short 
course of prednisone in the prevention of early relapse after emergency room treatment of acute asthma. N Engl J Med 1991;324:788-94.

11. O'Driscoll BR, Kalra S, Wilson M, et al. Double blind trial of steroid tapering in acute asthma. Lancet 1993;341:324-7.

12. Toogood JH, Baskerville J, Jennings B, Lefcoe NM, Johansson SA. Bioequivalent doses of prednisone and budesonide in moderate and severe asthma. J Allergy Clin Immunol 1989;84:688-700.

13. Juniper EF, Guyatt GH, Epstein RS, Ferrie PJ, Jaeschke R, Hiller TK. Evaluation of impairment of health related quality of life in asthma: development of a questionnaire for use in clinical trials. Thorax 1992;47:76-83.

14. American Thoracic Society. Guidelines to the diagnosis and treatment of asthma. Am Rev Respir Dis 1987;136:225-44.

15. Fiel SB, Swartz MA, Glanz K, Francis ME. Efficacy of short-term corticosteroid therapy in outpatient treatment of acute bronchial asthma. Am J Med 1983;75:259-62.

16. Majo J-L, Cartier A, Merland N, et al. Four times a day dosing frequency is better than twice a day regimen in subjects requiring a high dose inhaled corticosteroid, budesonide, to control moderate to severe asthma. Am Rev Respir Dis 1989;140:624-8.

17. Nana A, Younchaiyud P, Boe J, Lofdahl CG, Selroos O, Stahl E. High dose inhaled budesonide may substitute for oral therapy after an acute asthma attack. J Asthma 1998;35:647-55.

18. Levy ML, Stevenson C, Maslen T. Comparison of a short course of oral prednisone and fluticasone propionate in the treatment of adults with acute exacerbations of asthma in primary care. Thorax 1996;51:1087-92.

19. Griffiths C. Steroids in exacerbations of asthma: tablets or inhalers? Thorax 1996;51:1071-2. (Edit)

20. Rowe BH, Oxman AD. Performance of an asthma quality of life questionnaire in an outpatient setting. Am Rev Respir Dis 1993;148:675-81.
21. Noertjojo K, Turner MT, FitzGerald JM. An evaluation of the discriminative properties of quality of life measurements between severe hospitalized and outpatient asthma patients. Clin Invest Med 1997;20(Suppl 4):548. (Abst)

22. Skorodin MS. Side effects of corticosteroid administration. Am J Med 1986;82:8-15.

23. Awadh N, Al Mane F, Pare PD, FitzGerald JM. Acute myopathy after mechanical ventilation for acute asthma. Chest 1993;115;1627-31.

24. Ernst P, Spitzer W, Suissa S, et al. Risk of fatal and near fatal asthma relation to inhaled corticosteroid use. JAMA 1992;268:3462-4.

25. Weiss KB, Gergen PJ, Hodgson TA. An economic evaluation of asthma in the United States. N Engl J Med 1992;326:862-6.

26. Awadh N, Grunfeld A, FitzGerald JM. Health care costs associated with acute asthma. Can Respir J 1999;6:521-5.

27. Boulet L-P, Chapman K, Green L, FitzGerald JM. Asthma education. Chest 1994;106(Suppl):184S-97S.

28. Turner MO, Noertjojo K, Vedal S, Crump S, Bai T, FitzGerald JM. A prospective evaluation of risk factors for near fatal asthma: clinical characteristics. Am J Respir Crit Care Med 1998;157:1804-9.

29. Rowe BH, Bota GW, Fabris L, Therrien SA, Milner RA, Jacono J. Inhaled budesonide in addition to oral corticosteroids to prevent asthma relapse following discharge from the emergency department. JAMA 1999;281:2119-26.

30. Rodrigo G, Rodrigo C. Inhaled flunisolide for acute severe asthma. Am J Respir Crit Care Med 1998;157:698-703.

31. Svedmyr J, Nyberg E, Asbrink-Nilsson E, Hedlin G. Intermittent treatment with inhaled steroids for deterioration of asthma due to upper respiratory tract infections. Acta Paediatr 1995;84:884-8.

32. Sung L, Osmond MH, Klassen TP. Randomized controlled trial of inhaled budesonide as adjunct to oral prednisone in acute asthma. Acad Emerg Med 1998;5:209-13. 


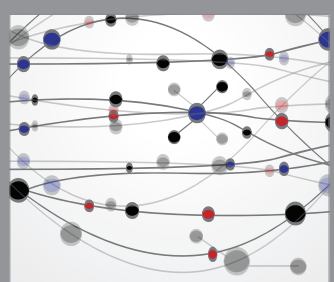

The Scientific World Journal
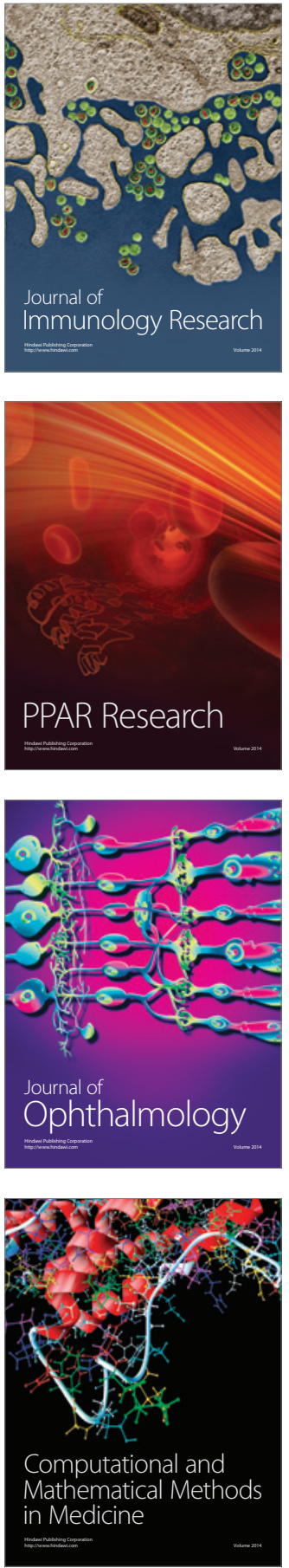

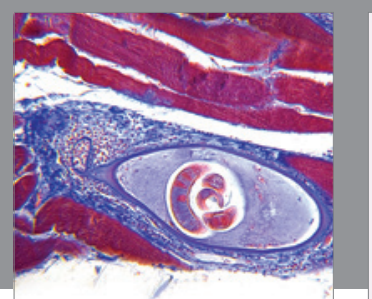

Gastroenterology Research and Practice

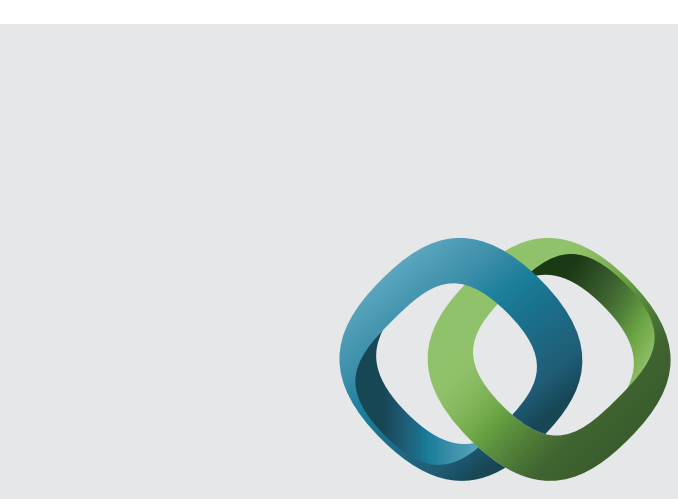

\section{Hindawi}

Submit your manuscripts at

http://www.hindawi.com
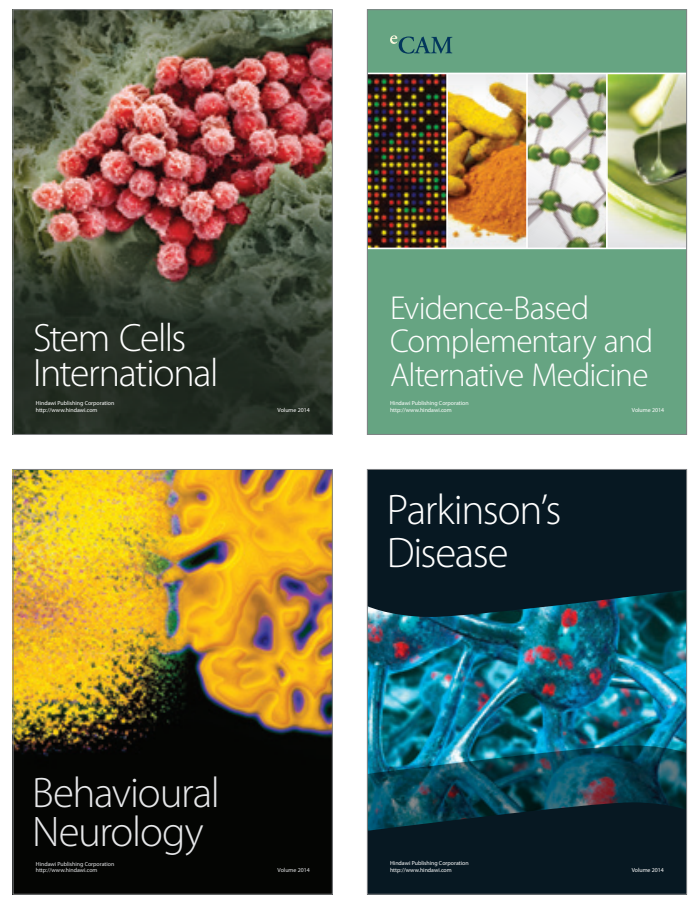
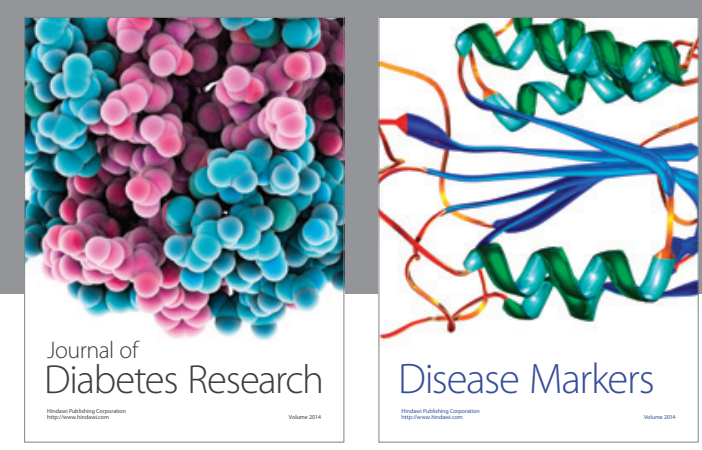

Disease Markers
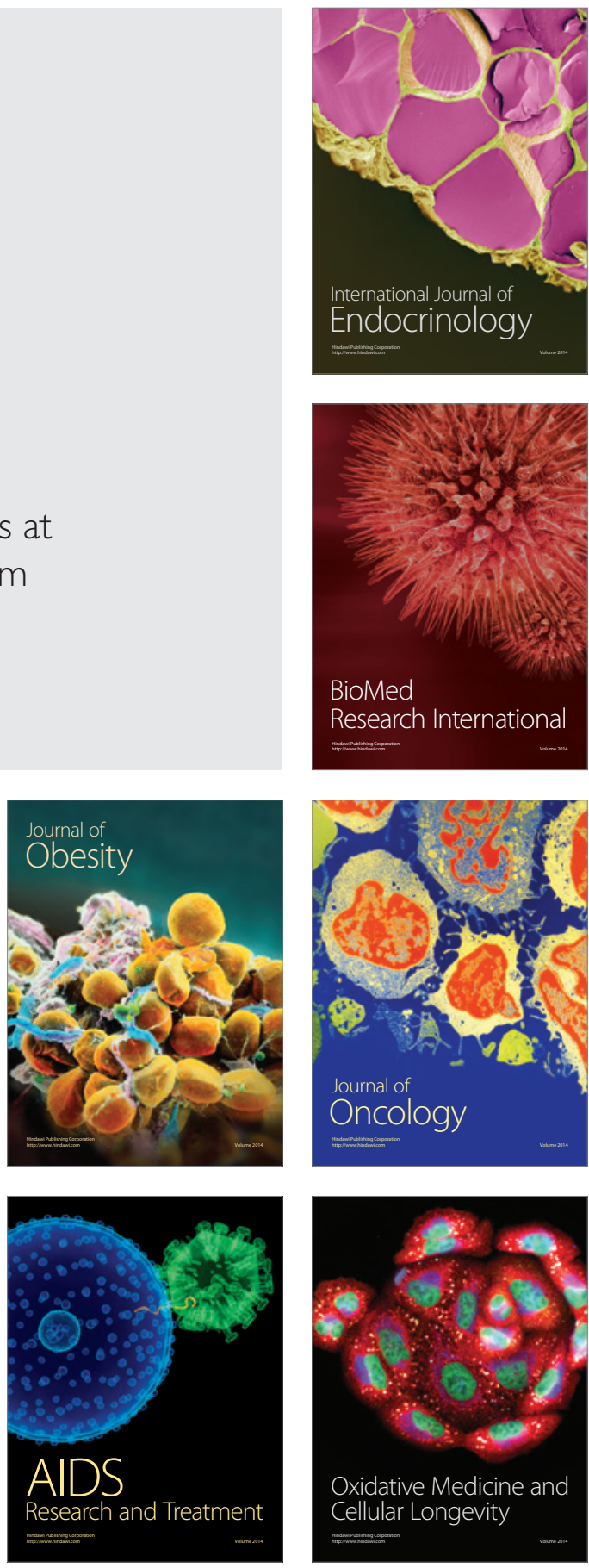